\title{
A New Approach for DL-EPR Testing of Thermo-Mechanically Processed Austenitic Stainless Steel ${ }^{1}$
}

\author{
S. Rahimi ${ }^{1}$, D. L. Engelberg ${ }^{2}$, T. J. Marrow ${ }^{3 *}$ \\ ${ }^{1}$ Advanced Forming Research Centre (AFRC), DMEM, University of Strathclyde, 85 Inchinnan Drive, \\ Inchinnan, Renfrewshire, PA4 9LJ \\ ${ }^{2}$ Corrosion \& Protection Centre, School of Materials, University of Manchester, Oxford Road, Manchester, M13 \\ 9PL, UK \\ ${ }^{3}$ Oxford Martin School and Department of Materials, University of Oxford, Parks Road, Oxford, OX1 3PH
}

\begin{abstract}
Standard test methods such as the Electrochemical Potentiokinetic Reactivation Test (EPR) and Double-Loop EPR test (DL-EPR) are commonly used to characterise sensitisation behaviour in austenitic stainless steels and nickel-based alloys. In this study, the DL-EPR test is augmented by large-area image analysis (IA) to characterise and quantify the networks of attacked grain boundaries. A new analysis approach that is based on a grain boundary cluster parameter is proposed to describe the network of corrosion susceptible grain boundaries, which may be estimated from electron backscatter diffraction (EBSD) data. This method may provide a better assessment of the relative DOS of different heats of austenitic stainless steels.
\end{abstract}

Keywords: Electro Potentiokinetic Reactivation (EPR), Image Analysis (IA), Intergranular Stress Corrosion Cracking (IGSCC), Degree of Sensitisation (DOS), Austenitic Stainless Steel

\section{Introduction}

Sensitisation of austenitic stainless steels is related to chromium depletion at grain boundaries, and is a major cause for intergranular corrosion (IGC) and intergranular stress corrosion cracking (IGSCC) $[1,2]$. Chromium depletion leads to a decrease in the local resistance to corrosion. Its rate of development can be influenced by the structure of grain boundaries [2-4]. Sensitisation can occur, for example, with welding, heat treatment (e.g. post weld, stress relief) or fast neutron irradiation $[2,5]$. The requirement for a simple, nondestructive and quantitative approach to determine the degree of sensitisation (DOS) in stainless steels and nickel based alloys led to the development of the electrochemical potentiokinetic reactivation (EPR) test method $[6,7]$. This addressed the difficulties to reliance on weight loss data or intergranular depth measurements from microscopic observations for samples that were not fully sensitised [8-10].

A number of modifications have since been introduced to improve the robustness of the test for sensitisation. These include, for example, the double loop EPR test (DL-EPR) [11, 12], a simplified EPR procedure based on a combination of features from the EPR and DL-EPR methods [13], and also modifications to the test electrolyte for specific material applications $[6,14,15]$. A disadvantage of the EPR test is its sensitivity to the surface condition of the specimen. This was resolved in the DL-EPR test [12], and the simplified EPR method [13].

\footnotetext{
${ }^{1}$ NOTICE: this is the author's version of a work that was accepted for publication in Corrosion Science. Changes resulting from the publishing process, such as peer review, editing, corrections, structural formatting, and other quality control mechanisms may not be reflected in this document. Changes may have been made to this work since it was submitted for publication. A definitive version was subsequently published in Corrosion Science 53 (12) , pp. 4213-4222, DOI: 10.1016/j.corsci.2011.08.033

- The work was performed at the Materials Performance Centre (MPC), School of Materials in the University of Manchester. SR and TJM have since moved to new positions.
} 
In the DL-EPR test the polarisation curve in the anodic direction (i.e. the activation loop), associated with charges from the whole specimen surface, is compared to the polarisation curve in the cathodic direction (i.e. the reactivation loop) $[6,13]$. The reactivation loop gives a response predominantly from the corrosion susceptible chromium-depleted grain boundaries. This allows direct comparison of the electrical charge from attacked boundaries, to the charge from the whole specimen surface. Microstructural factors such as grain size are not accounted for in the standard DL-EPR test. However, in a further development, the charge from the cathodic scan is normalised by a measure of either grain boundary length or grain boundary area, in order to compare the DOS of microstructures with different grain sizes [16, 17]. These normalisations are based on the assumptions that all the grain boundaries will sensitise similarly and the width of chromium depletion in all boundaries is also constant $\left(10^{-4} \mathrm{~cm}\right)$. However, it has been well established that the sensitisation behaviour depends on the structure of grain boundaries [2, 5, 18, 19]. The population of boundary types can also vary quite significantly with thermo-mechanical processing [20, 21], and this is not taken into account in the current assessment methods.

Grain boundaries may be described and classified by their $\Sigma$ values in the framework of coincidence site lattice (CSL) model, in which the $\Sigma$ notation gives the reciprocal density of the coinciding sites of the interpenetrating lattices of the two grains [22, 23]. It therefore depends on their relative crystallographic orientations. As a first approximation, high energy grain boundaries with higher $\Sigma$ value $(\Sigma>29)$ are more prone to chromium depletion and therefore corrosion, while low energy grain boundaries with low $\Sigma$ values $(\Sigma \leq 29)$ have superior corrosion resistance [24-26]. This is not a full description, since it is actually the grain boundary plane that determines sensitisation resistance [27], but the CSL model provides a fair approximation. Sensitisation resistant grain boundaries can interrupt the network of corrosion susceptible grain boundaries, which affects the intergranular stress corrosion cracking (IGSCC) resistance in austenitic stainless steels [28, 29].

In this study a new approach is introduced to assess DL-EPR test data; it aims to improve DOS measurement in austenitic stainless steel microstructures. In the first stage of this study, results from standard DL-EPR assessment methods [16, 17] are compared to the new approach, which is based on the measured length and area of the attacked grain boundary network obtained from image analysis (IA) [30], rather than simple estimates. The paper then investigates the relationship between the networks of attacked grain boundaries, identified after corrosion tests, and the network of higher energy CSL boundaries $(\Sigma>29)$, obtained by EBSD. A parameter defining the cluster compactness, which has been proposed to describe the breakup of the corrosion susceptible grain boundary network [20], is used to compare these differently observed networks. The objective is to provide a better measure of intergranular corrosion and stress corrosion cracking resistance in sensitised microstructures, using an estimate of the susceptible network of grain boundaries. It is found that this may be obtained in the non-sensitised condition using EBSD methods.

\section{Experimental}

A mill annealed Type 304 austenitic stainless steel plate was used in this study, with the chemical composition given in Table 1 . Rectangular specimens with dimensions of $210 \times 13$ $\times 8(\mathrm{~L} \times \mathrm{W} \times \mathrm{T})$ were cut from the plate with their length parallel to the rolling direction (RD) of the as received plate and solution annealed at $1050^{\circ} \mathrm{C}$ for two hours in an argon atmosphere (SA). Thermo-mechanical treatments were then carried out on the solution annealed specimens by tensile straining with a cross-head displacement of $2 \mathrm{~mm} / \mathrm{min}$. Absolute tensile strains of 5\%,10\%,20\%, and 30\% were introduced. For each level of 
strain, samples were subsequently heat treated at $900^{\circ} \mathrm{C}, 950^{\circ} \mathrm{C}$ and $1050^{\circ} \mathrm{C}$ with exposures of up to 200 hours. These treatments are reported by the percentage of tensile deformation, annealing temperature and annealing time. For instance 20\%/950/26 represents 20\% deformation, followed by annealing at $950^{\circ} \mathrm{C}$ for 26 hours. Samples from the as received (As Rec) and 2 hours solution annealed (SA) microstructures were also kept for comparison. An overview of all thermo-mechanically processed microstructures is given in Table 2.

Table 1: Nominal composition of type 304 austenitic stainless steel (wt.\%)

\begin{tabular}{|c|c|c|c|c|c|c|c|c|c|}
\hline Elements & Fe & Cr & Ni & C & Mn & P & S & Si & N \\
\hline Wt. \% & Bal. & 18.15 & 8.60 & 0.055 & 1.38 & 0.032 & 0.005 & 0.45 & 0.038 \\
\hline
\end{tabular}

Table 2: The thermo-mechanical treatment processes used for microstructure design and.

\begin{tabular}{|c|c|c|c|}
\hline \multirow{3}{*}{ Initial Status } & \multicolumn{3}{|c|}{ Thermo-Mechanical Processing } \\
\cline { 2 - 4 } & Strain (\%) & Temperature $\left(\mathbf{~}^{\circ} \mathbf{C}\right)$ & Annealing Time (Hour) \\
\hline \multirow{3}{*}{$\begin{array}{c}\text { Solution Annealed } \\
\left(2 \text { hours at } 1050^{\circ} \mathrm{C}\right)\end{array}$} & 5 & 900 & 1,26 \\
\cline { 2 - 4 } & \multirow{2}{*}{20} & 950 & 1.5 \\
\cline { 2 - 4 } & \multirow{2}{*}{20} & 900 & $1,15,26$ \\
\cline { 2 - 4 } & \multirow{2}{*}{30} & 900 & $1,15,26$ \\
\cline { 2 - 4 } & & 950 & $1,15,26,48,75,100,200$ \\
\cline { 2 - 4 } & & 9050 & $1,11,26,48,75,100$ \\
\cline { 2 - 4 } & & 950 & $0.16,0.5,1$ \\
\hline
\end{tabular}

\section{Sensitisation and Assessment}

The As Rec, SA materials along with 20\%/950/26 and 30\%/950/26 treated microstructures were sensitised at $650^{\circ} \mathrm{C}$ for times between 1 and 20 hours. The other thermo-mechanically processed microstructures were fully sensitised at $650^{\circ} \mathrm{C}$ for 20 hours only. All sensitised microstructures were then DL-EPR tested $[12,16,17]$ in a solution of $0.5 \mathrm{M} \mathrm{H}_{2} \mathrm{SO}_{4}+0.01 \mathrm{M}$ KSCN, de-aerated with nitrogen, at ambient temperature. A standard three-electrode electrochemical cell with platinum counter electrode and saturated calomel electrode (SCE) was used. In order to determine the activation current peak $\left(I_{a}\right)$, samples were anodically polarised from open circuit potential (OCP) to a passivation potential of $+300 \mathrm{mV}$ SCE, using a sweep rate of $1.67 \mathrm{mV} / \mathrm{s}$. The applied potential was then reversed, and the sample cathodically swept back to the initial potential (OCP) to determine the re-activation current peak $\left(I_{r}\right)$. At least three measurements were acquired per microstructure and the error bars are reported as the maximum and minimum of the assessments, unless stated otherwise. In all cases, the microstructure assessment is on the plane perpendicular to the original rolling direction of the microstructure (i.e. ND-TD).

Data from these tests were evaluated with standard DL-EPR assessment methods comprising, (i) the ratio of maximum current of the re-activation $\left(I_{r}\right)$ polarisation sweep to the maximum current of the anodic activation $\left(I_{a}\right)$ sweep $[12,13,16]$, (ii) the same ratio, normalized by the estimated dimension of the susceptible grain boundary network length, $\left(I_{r} / I_{a}\right)_{G B L}$ [16], and (iii) the same ratio normalized by the estimated dimension of the area of the susceptible GB 
network, $\left(I_{r} / I_{a}\right)_{G B A}$ [16]. This normalisation by grain boundary length or area is commonly known as Cihal's method [16]. The length of the potentially susceptible grain boundary network is estimated by converting the measured grain size into a grain boundary length. The grain size was obtained from electron backscatter diffraction (EBSD) data (see next section for details). The susceptible grain boundary area is obtained from the length by assuming a constant and uniform width of boundary attack $\left(10^{-4} \mathrm{~cm}\right)$ [16]. The standard assessment methods to calculate the DOS are given in Equation 1, Equation 2 and Equation 3, respectively [16]. Equation 2 and Equation 3 give the same ranking of relative DOS of microstructures.

$D O S=I_{r} / I_{a}$

Equation 1

$\left(\frac{I_{r}}{I_{a}}\right)_{G B L}=\frac{I_{r}}{L_{G B L}} / \frac{I_{a}}{A_{s}}=\frac{I_{r}}{10 L_{A} \cdot A_{s}} / \frac{I_{a}}{A_{s}}=\frac{I_{r}}{10 L_{A} \cdot I_{a}}=\frac{I_{r}}{I_{a} \cdot 10 \sqrt{2^{G+5}}} \times 10^{4}(\mu m)$

Equation 2

$\left(\frac{I_{r}}{I_{a}}\right)_{G B A}=\frac{I_{r}}{S_{G B A}} / \frac{I_{a}}{A_{s}}=\frac{I_{r}}{S_{A} \cdot A_{s}} / \frac{I_{a}}{A_{s}}=\frac{I_{r}}{I_{a} S_{A}}=\frac{I_{r}}{I_{a} 10^{-3} \sqrt{2^{G+5}}}$

Equation 3

$I_{r}$ : Maximum current density of the re-activation curve $\left(\mu \mathrm{A} . \mathrm{cm}^{-2}\right)$

$I_{a}$ : Maximum current density of the anodic polarisation curve $\left(\mu \mathrm{A} \cdot \mathrm{cm}^{-2}\right)$

$A_{S}$ : Total exposed surface area or specimen surface area $\left(\mathrm{cm}^{2}\right)$

$S_{A}$ : Grain boundary area per unit of specimen area $\left(S_{A}=4 \times 10^{-3} \sqrt{2^{G+1}}\right)$.

$G$ : Grain size number, calculated from grain size as in BS ISO 643 [31]. Note that the grain size number has been calculated by excluding the twin grain boundaries $(\Sigma 3)$.

$S_{G B A}$ : Total grain boundary area, $S_{G B A}=S_{A} \times A_{S}$.

$L_{G B L}$ : Total length of grain boundaries, $L_{G B L}=10 \times L_{A} \times A_{S}(\mathrm{~cm})$.

$L_{A}$ : Length of grain boundary per unit of specimen area, $L_{A}=\sqrt{2^{G+5}}\left(\mathrm{~mm}^{-1}\right)$.

Optical images of the attacked surfaces were obtained after DL-EPR testing. Individual images, each with a dimension of $1100 \mu \mathrm{m} \times 880 \mu \mathrm{m}$, were stitched together using Adobe Photoshop CS, to create a single high-resolution image with a total surface area of $28 \mathrm{~mm}^{2}$ (Figure 1). Image analysis (IA) tools (implemented in MatLab 7.0.1) were used to threshold and segment the image and thereby to measure the dark (i.e. attacked) regions. The total area of the attacked surface was determined by pixel counting. The segmented images were filtered to exclude contributions from pits and isolated regions of delta-ferrite, although these contributed less than 3\% to the total segmented area. The widths of several thousands of corroded boundaries, intercepted by a line in a high-resolution image, were measured for each microstructure, with the mean and standard deviation extracted. The attacked grain boundary length was calculated by dividing the measured total attacked area by the mean attacked boundary width. This method provides quantitative measures of the real attacked grain boundary network for each microstructure, which were then compared to the estimated length and area of grain boundaries from Equation 2 and Equation 3. 


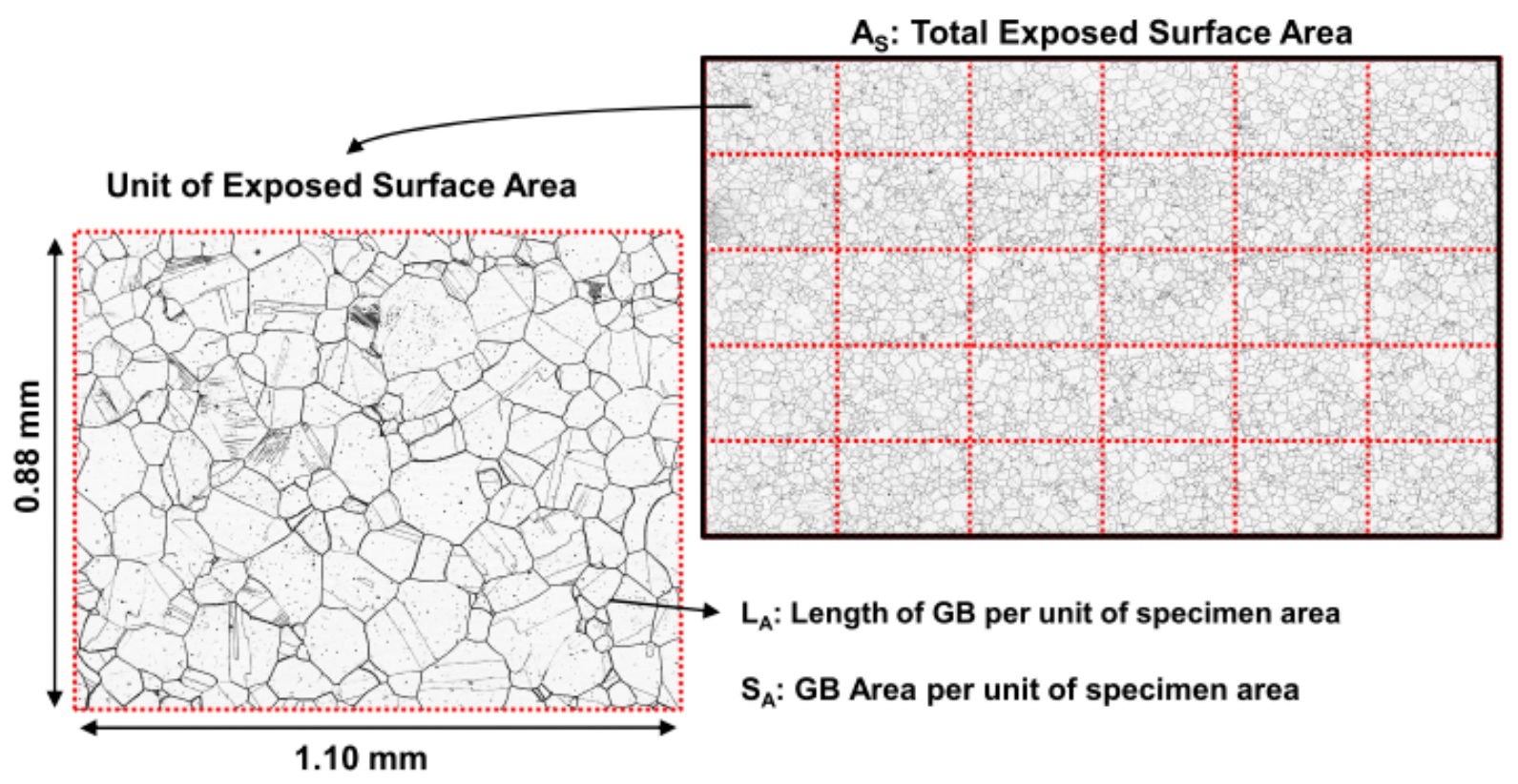

Figure 1: Optical microscopy image of the network of corroded grain boundaries after DL-EPR testing, with emphasise on the length and area of grain boundaries in a unit of specimen area.

\section{EBSD Assessment}

Electron-backscatter diffraction (EBSD) maps were collected from all microstructures on planes that were perpendicular to the rolling direction (RD). The typical scan area was $600 \mu \mathrm{m} \times 450 \mu \mathrm{m}$ with a step size of $1.5 \mu \mathrm{m}$. At least 6 overlapping areas $(3 \times 2$ array $)$ were analysed for each sample, and stitched to form a larger map with approximate dimensions of $1800 \mu \mathrm{m} \times 900 \mu \mathrm{m}$. The HKL-EBSD system used was equipped with low light CCD camera (Nordlys II), interfaced to a Philips XL-30 FEG-SEM. The HKL Channel 5 software was used to stitch the maps together and characterise the data, using Brandon's criterion and the coincidence site lattice (CSL) model framework [23]. A $15^{\circ}$ threshold was used for high angle grain boundaries (HAGB), and a minimum misorientation angle of $2^{\circ}$ for low angle boundaries. Grain boundaries with $\Sigma \leq 29$ were regarded as special or low energy boundaries, including low angle grain boundaries (LAGBs $-\Sigma 1$ ).

\section{Cluster Analysis}

The dimensions of the largest connected cluster of connected dark pixels, $M$, were obtained by image analysis of EBSD maps of the grain boundaries (excluding low- $\Sigma$ CSL $(\Sigma \leq 29)$ boundaries), and the segmented optical micrographs of grain boundaries attacked by DL-EPR testing. This cluster was assumed to be representative of the microstructure, and its dimensions were used to calculate the cluster compactness $(C)$ of the grain boundary networks in different microstructures. The cluster compactness is given in Equation 4 [20].

$$
C=\frac{L_{M} \cdot D}{A}
$$

Equation 4

Where $L_{M}$ is the length of the largest connected cluster, $D$ is the grain size (disregarding twins) and $A$ is the area of the smallest square-box that bounds the largest connected cluster (Figure 2). The cluster compactness calculated from image analysis of optical micrographs 
of the attacked grain boundaries is denoted as $C_{O I A}$ and that obtained from EBSD maps as $C_{E B S D}$.

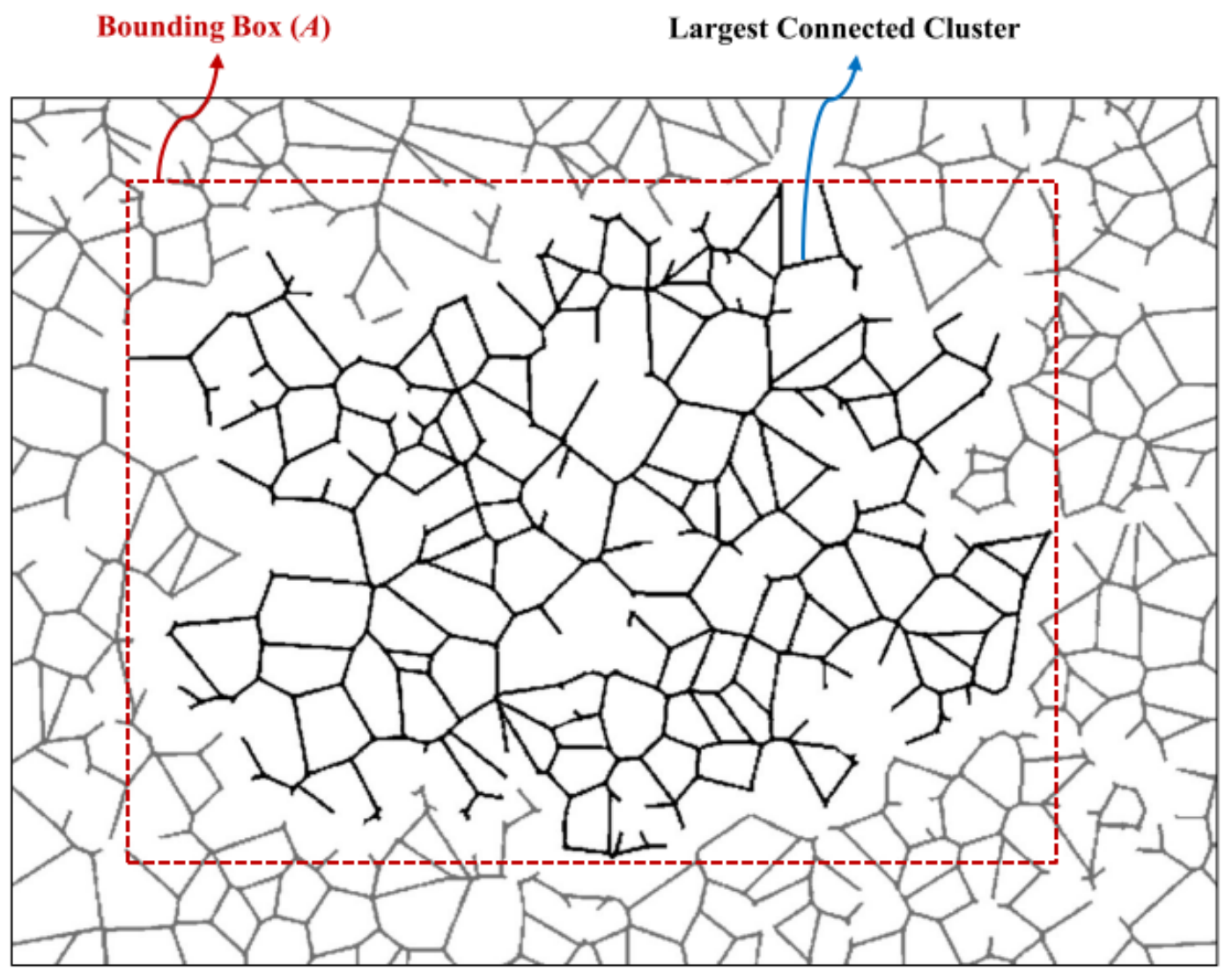

Figure 2: Schematic representation of a cluster of attacked grain boundaries in fully sensitised microstructure. The smallest box (A) that bounds the largest connected cluster is outlined by broken lines. It is not uncommon for the largest connected cluster to percolate across the full image, in which case the bounding box is the image size. Representative measurements are obtained if the image size is large compared to the microstructure scale $[20]$.

The cluster compactness is a non-dimensional parameter that measures the density of a cluster body (i.e. the network of corrosion susceptible grain boundaries or network of random boundaries $(\Sigma>29))$. The cluster mass $(M)$ is the number of pixels in a cluster. The cluster length $(L)$ is calculated by dividing the cluster mass by the average grain boundary width $\left(W_{G B}\right)$. The grain boundary width for the network of attacked grain boundaries is measured by image analysis. In the case of EBSD assessment, the boundary width has an arbitrary constant value. The cluster compactness is described as the number of grain boundaries in the cluster length (i.e. $L / D$, where $\mathrm{D}$ is the average grain size), relative to a measure of the total number of boundaries in a fully compact cluster of the same area (i.e. $A / D^{2}$ ). Equation 4 is obtained for the maximum cluster length, $L_{M}$. By this measure, for example, a fully compact cluster in a 2D microstructure of square grains would have a cluster compactness of 1. A fully compact cluster is therefore one in which all grain boundaries are sensitised. A less compact cluster of the same area, with fewer sensitised boundaries and hence with lower mass, would have lower cluster compactness [20,21]. These are schematically shown for network of square grains in Figure 3. The cluster compactness is therefore a measure of the number of sensitised grain boundaries. 


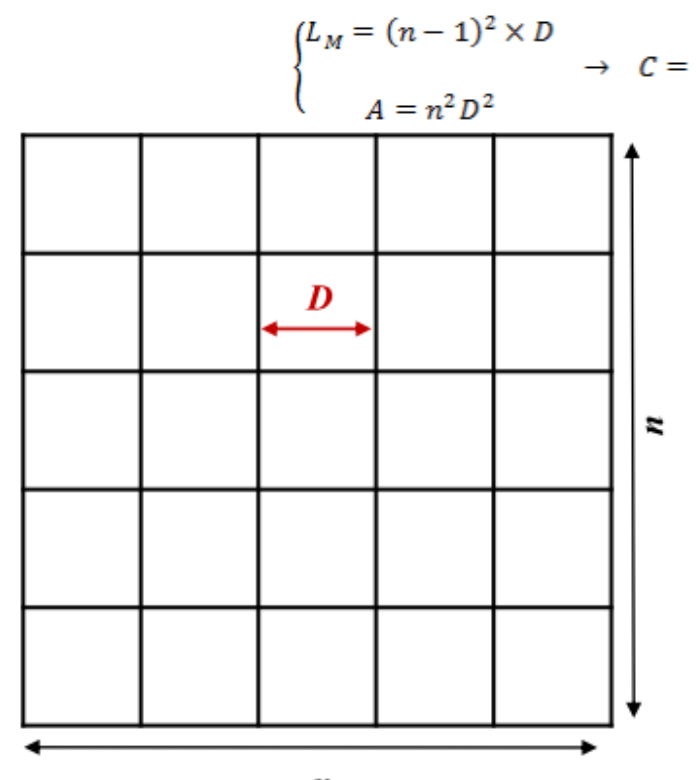

(a) $n$ (b)

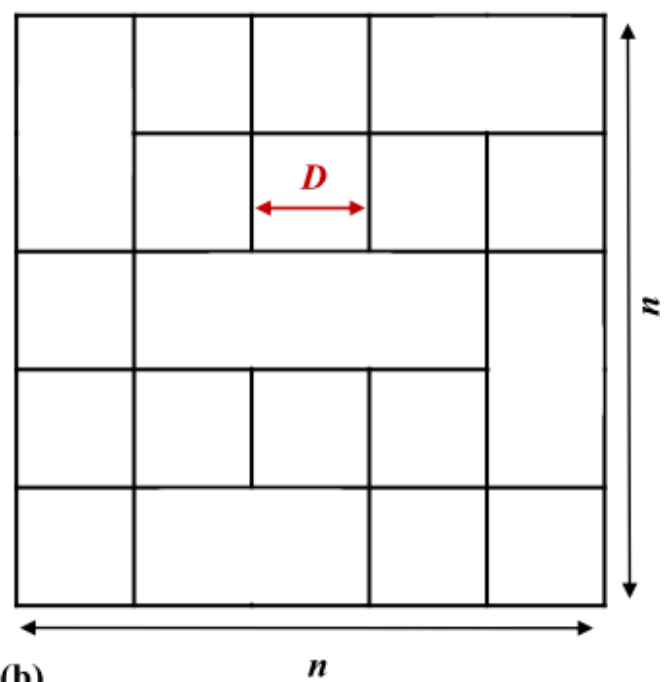

Figure 3: Schematic representation of a network of susceptible boundaries with square grains (size D) (a) fully compact boundary cluster, for $n>>1, C \sim 1$ and (b) the same area with fewer susceptible boundaries and hence $\mathrm{C}<1$.

\section{Results}

Data for the grain size, grain boundary character distribution (GBCD) and DL-EPR ratios from Equation 1, after sensitisation for 20 hours, are summarized in Table 3. Both length and number fractions of the GBCD are summarised, to provide a full description of grain boundary statistics. Figure 4 envelopes the range of microstructure and grain sizes investigated.

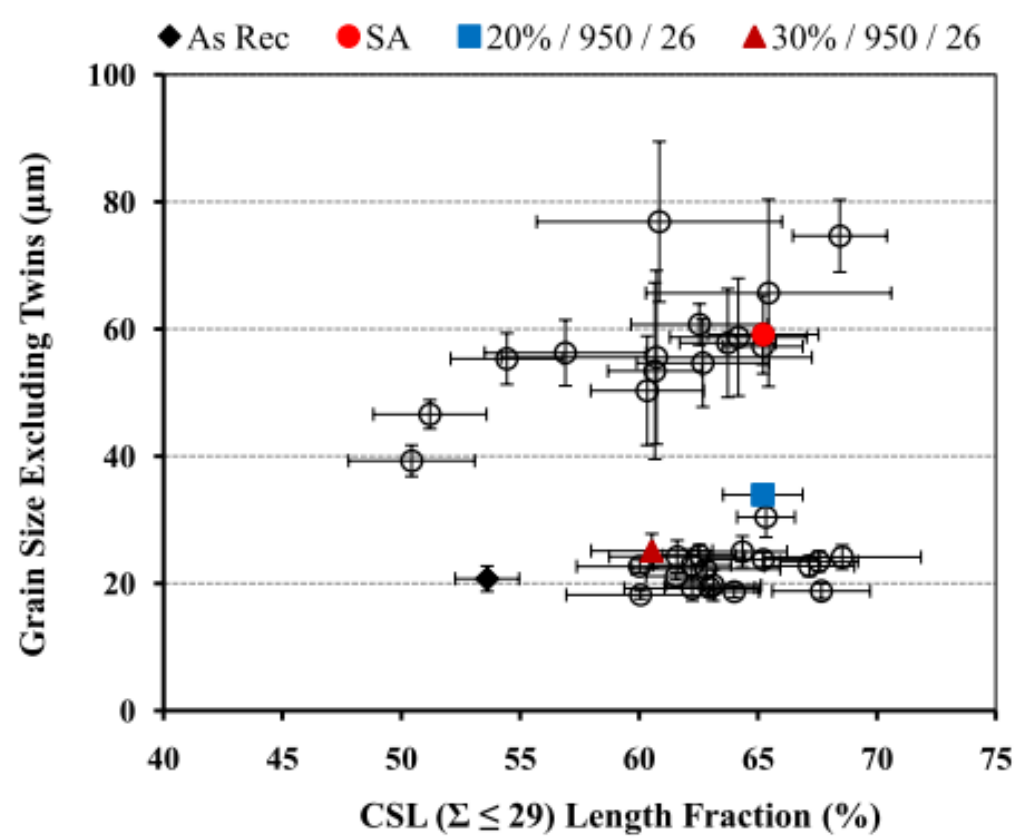

Figure 4: Grain size (GS) including twins versus the length fraction of low- $\Sigma$ CSL boundaries ( $\Sigma$ $\leq 29)$ for all microstructures investigated in this study. The error bars are one standard deviation. 
Table 3: Grain boundary character distribution (GBCD), grain sizes and measured DOS (Equation 1) ratios of all investigated microstructures.

\begin{tabular}{|c|c|c|c|c|c|c|c|c|c|}
\hline \multirow{2}{*}{$\begin{array}{c}\text { Microstructure } \\
\left(\% /{ }^{0} \mathrm{C} / \mathrm{hr}\right)\end{array}$} & \multicolumn{2}{|c|}{$\Sigma 3$} & \multicolumn{2}{|c|}{ LAGB $(\Sigma 1)$} & \multicolumn{2}{|c|}{ Low $\Sigma(\Sigma 1-29)$} & \multicolumn{2}{|c|}{ Grain Size $(\mu \mathrm{m})$} & \multirow{2}{*}{$\begin{array}{l}\text { DOS } \\
\left(\mathbf{I}_{\mathbf{r}} / \mathbf{I}_{a}\right)\end{array}$} \\
\hline & $\begin{array}{c}\text { Length } \\
(\%)\end{array}$ & $\begin{array}{c}\text { Number } \\
(\%)\end{array}$ & $\begin{array}{c}\text { Length } \\
(\%)\end{array}$ & $\begin{array}{c}\text { Number } \\
(\%)\end{array}$ & $\begin{array}{c}\text { Length } \\
(\%)\end{array}$ & $\begin{array}{c}\text { Number } \\
(\%)\end{array}$ & $\begin{array}{l}\text { Including } \\
\text { Twins }\end{array}$ & $\begin{array}{c}\text { Excluding } \\
\text { Twins }\end{array}$ & \\
\hline SA & $57.3 \pm 3.0$ & $34.5 \pm 1.5$ & $9.5 \pm 6.0$ & $8.5 \pm 4.6$ & $65.2 \pm 2.3$ & $47.9 \pm 2.8$ & $37.6 \pm 12.4$ & $59.1 \pm 6.2$ & $0.22 \pm 0.01$ \\
\hline $5 / 900 / 1$ & $58.5 \pm 2.7$ & $33.2 \pm 1.3$ & $15.7 \pm 3.4$ & $10.6 \pm 1.4$ & $68.4 \pm 2.0$ & $48.8 \pm 2.2$ & $47.1 \pm 7.1$ & $74.6 \pm 5.7$ & $0.22 \pm 0.01$ \\
\hline $10 / 900 / 1$ & $54.2 \pm 4.1$ & $31.2 \pm 1.5$ & $10.6 \pm 3.9$ & $13.0 \pm 2.1$ & $63.7 \pm 2.0$ & $45.2 \pm 1.1$ & $37.4 \pm 10.7$ & $57.8 \pm 8.5$ & $0.29 \pm 0.01$ \\
\hline $10 / 900 / 15$ & $51.0 \pm 1.5$ & $28.7 \pm 1.0$ & $11.2 \pm 3.3$ & $10.6 \pm 2.1$ & $60.7 \pm 2.0$ & $43.45 \pm 1.7$ & $35.3 \pm 9.6$ & $53.4 \pm 13.9$ & $0.26 \pm 0.01$ \\
\hline $10 / 900 / 26$ & $54.1 \pm 4.6$ & $27.6 \pm 3.2$ & $9.3 \pm 3.0$ & $9.9 \pm 5.3$ & $62.5 \pm 2.9$ & $43.1 \pm 0.3$ & $39.5 \pm 9.1$ & $60.7 \pm 3.2$ & $0.26 \pm 0.01$ \\
\hline $20 / 900 / 1$ & $47.8 \pm 0.9$ & $30.9 \pm 1.6$ & $27.0 \pm 6.4$ & $25.6 \pm 5.1$ & $67.7 \pm 2.1$ & $57.0 \pm 3.3$ & $12.7 \pm 2.6$ & $18.8 \pm 1.2$ & $0.33 \pm 0.01$ \\
\hline $30 / 900 / 15$ & $49.9 \pm 3.2$ & $34.0 \pm 1.6$ & $4.7 \pm 4.4$ & $3.3 \pm 1.5$ & $63.0 \pm 1.9$ & $52.2 \pm 3.3$ & $12.9 \pm 1.7$ & $19.3 \pm 0.4$ & $0.43 \pm 0.01$ \\
\hline $30 / 900 / 26$ & $56.5 \pm 2.6$ & $35.7 \pm 1.5$ & $2.4 \pm 1.2$ & $2.1 \pm 0.9$ & $67.6 \pm 1.6$ & $55.8 \pm 1.5$ & $15.0 \pm 2.0$ & $23.4 \pm 1.6$ & $0.40 \pm 0.01$ \\
\hline $30 / 900 / 48$ & $51.9 \pm 2.8$ & $32.1 \pm 2.2$ & $2.2 \pm 0.5$ & $2.4 \pm 0.5$ & $62.2 \pm 2.9$ & $50.1 \pm 2.7$ & $12.6 \pm 2.4$ & $19.2 \pm 1.9$ & $0.38 \pm 0.01$ \\
\hline $30 / 900 / 75$ & $53.6 \pm 1.6$ & $33.7 \pm 2.0$ & $3.0 \pm 0.8$ & $3.1 \pm 0.5$ & $64.0 \pm 1.1$ & $50.4 \pm 2.1$ & $12.5 \pm 2.1$ & $18.7 \pm 0.9$ & $0.36 \pm 0.01$ \\
\hline $30 / 900 / 100$ & $50.7 \pm 0.8$ & $33.9 \pm 0.8$ & $3.8 \pm 2.6$ & $3.8 \pm 2.7$ & $61.6 \pm 1.3$ & $50.4 \pm 1.2$ & $14.0 \pm 2.6$ & $21.1 \pm 0.6$ & $0.37 \pm 0.01$ \\
\hline $30 / 900 / 200$ & $52.8 \pm 2.0$ & $32.8 \pm 1.3$ & $2.5 \pm 0.5$ & $3.3 \pm 0.6$ & $63.1 \pm 2.0$ & $49.0 \pm 1.8$ & $12.9 \pm 3.0$ & $19.7 \pm 2.4$ & $0.33 \pm 0.01$ \\
\hline $5 / 950 / 1.5$ & $47.9 \pm 6.5$ & $27.1 \pm 1.5$ & $15.3 \pm 5.3$ & $9.4 \pm 0.8$ & $60.8 \pm 5.1$ & $44.2 \pm 1.6$ & $52.0 \pm 8.9$ & $76.9 \pm 12.6$ & $0.33 \pm 0.01$ \\
\hline $10 / 950 / 1$ & $56.2 \pm 5.4$ & $31.2 \pm 2.4$ & $11.8 \pm 5.3$ & $9.7 \pm 4.3$ & $65.4 \pm 5.1$ & $44.2 \pm 4.0$ & $41.8 \pm 14.2$ & $65.6 \pm 14.7$ & $0.24 \pm 0.01$ \\
\hline $10 / 950 / 15$ & $53.9 \pm 2.7$ & $31.4 \pm 3.0$ & $9.5 \pm 4.5$ & $8.7 \pm 2.5$ & $62.7 \pm 2.8$ & $44.2 \pm 4.1$ & $35.5 \pm 13.4$ & $54.6 \pm 6.9$ & $0.22 \pm 0.01$ \\
\hline $30 / 950 / 11$ & $50.0 \pm 2.1$ & $32.5 \pm 0.9$ & $4.0 \pm 1.0$ & $3.9 \pm 0.7$ & $60.0 \pm 2.6$ & $46.7 \pm 1.4$ & $15.1 \pm 3.0$ & $22.7 \pm 1.0$ & $0.37 \pm 0.01$ \\
\hline $30 / 950 / 15$ & $47.0 \pm 2.8$ & $31.0 \pm 2.2$ & $11.3 \pm 4.4$ & $26.1 \pm 4.6$ & $67.1 \pm 1.9$ & $53.6 \pm 4.1$ & $15.1 \pm 3.8$ & $22.7 \pm 1.6$ & $0.34 \pm 0.01$ \\
\hline $30 / 950 / 26$ & $51.8 \pm 2.3$ & $33.1 \pm 1.4$ & $3.5 \pm 1.2$ & $2.9 \pm 0.5$ & $62.2 \pm 1.6$ & $49.2 \pm 1.7$ & $14.9 \pm 3.3$ & $22.8 \pm 2.5$ & $0.30 \pm 0.01$ \\
\hline $30 / 950 / 48$ & $51.4 \pm 2.7$ & $33.6 \pm 2.2$ & $2.5 \pm 0.4$ & $2.6 \pm 0.5$ & $61.6 \pm 2.9$ & $49.5 \pm 2.7$ & $16.0 \pm 3.4$ & $24.2 \pm 2.6$ & $0.33 \pm 0.01$ \\
\hline $30 / 950 / 75$ & $52.5 \pm 1.6$ & $33.2 \pm 1.0$ & $7.4 \pm 3.3$ & $11.6 \pm 3.1$ & $64.3 \pm 1.9$ & $48.6 \pm 3.0$ & $16.1 \pm 4.6$ & $25.0 \pm 2.4$ & $0.32 \pm 0.01$ \\
\hline $30 / 950 / 100$ & $51.0 \pm 1.9$ & $31.8 \pm 1.0$ & $2.5 \pm 0.7$ & $3.6 \pm 1.2$ & $60.5 \pm 2.5$ & $47.1 \pm 1.2$ & $16.6 \pm 4.0$ & $25.1 \pm 2.7$ & $0.29 \pm 0.01$ \\
\hline $20 / 1050 / 0.16$ & $46.0 \pm 3.7$ & $31.3 \pm 2.8$ & $11.4 \pm 7.4$ & $8.8 \pm 4.7$ & $56.9 \pm 3.4$ & $45.9 \pm 5.3$ & $38.6 \pm 12.0$ & $56.2 \pm 5.2$ & $0.27 \pm 0.01$ \\
\hline $20 / 1050 / 0.5$ & $46.7 \pm 3.2$ & $29.8 \pm 2.9$ & $17.7 \pm 3.3$ & $15.8 \pm 5.5$ & $60.3 \pm 2.4$ & $46.5 \pm 5.7$ & $34.4 \pm 8.0$ & $50.3 \pm 8.6$ & $0.23 \pm 0.01$ \\
\hline $20 / 1050 / 1$ & $46.0 \pm 3.3$ & $29.6 \pm 2.1$ & $6.8 \pm 3.0$ & $6.0 \pm 2.4$ & $54.4 \pm 2.4$ & $40.8 \pm 2.2$ & $37.9 \pm 10.5$ & $55.3 \pm 4.0$ & $0.22 \pm 0.01$ \\
\hline $30 / 1050 / 0.16$ & $43.5 \pm 2.3$ & $27.3 \pm 1.5$ & $4.0 \pm 0.4$ & $4.2 \pm 0.8$ & $50.4 \pm 2.6$ & $37.8 \pm 2.0$ & $27.7 \pm 7.0$ & $39.3 \pm 2.4$ & $0.28 \pm 0.01$ \\
\hline $30 / 1050 / 0.5$ & $43.4 \pm 2.4$ & $26.2 \pm 1.4$ & $5.5 \pm 2.0$ & $6.0 \pm 1.4$ & $51.2 \pm 2.4$ & $38.2 \pm 2.2$ & $32.6 \pm 8.6$ & $46.6 \pm 2.3$ & $0.22 \pm 0.01$ \\
\hline $30 / 1050 / 1$ & $55.4 \pm 2.5$ & $35.8 \pm 1.6$ & $2.4 \pm 0.8$ & $2.6 \pm 0.8$ & $65.2 \pm 1.7$ & $52.4 \pm 1.6$ & $39.2 \pm 11.3$ & $57.2 \pm 2.8$ & $0.23 \pm 0.01$ \\
\hline
\end{tabular}


The data for measured maximum current density of the anodic polarisation curves $\left(I_{a}\right)$ for all microstructures in this study have been grouped according to their sample area. Each sample area represents a specific tensile straining condition with, for example, the smallest sample size $\left(64 \mathrm{~mm}^{2}\right)$ being associated with $30 \%$ strained samples. Figure 5 shows an increasing trend in $I_{a}$ with increasing sample area. This confirms that the activation current is dominated by sample area, i.e. active dissolution of the surface. The development of the DOS (Equation 1) as a function of sensitisation time in four selected microstructures is shown in Figure 6. The DOS increases with sensitisation time, and approaches saturation with longer exposures (i.e. $>8 \mathrm{hrs}$ ). Optical micrographs confirmed that all four microstructures are in fully sensitised condition after 20 hours at $650^{\circ} \mathrm{C}$ (i.e. Figure 1).

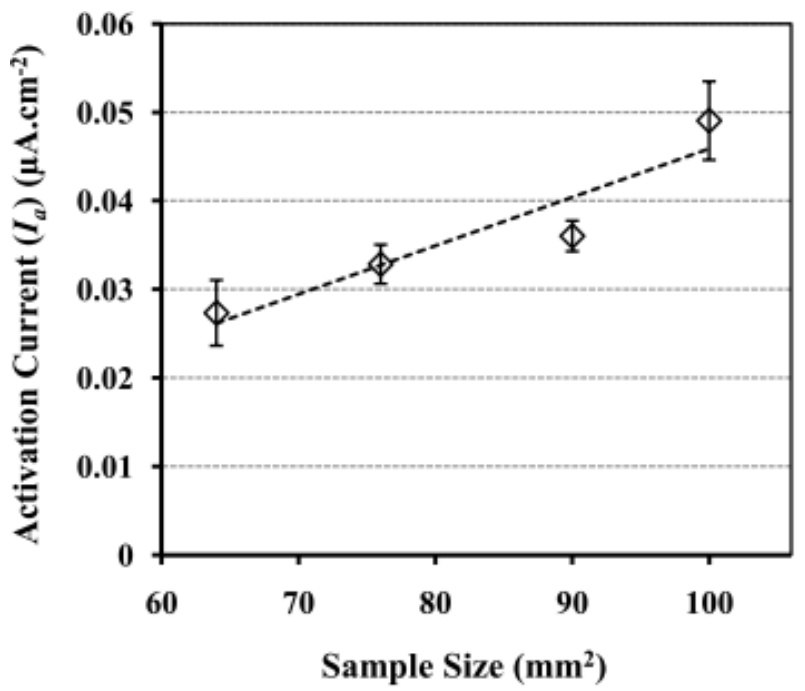

Figure 5: Maximum current density of the anodic polarisation $\left(I_{a}\right)$ as a function of sample area. The error bars show the standard deviations of more than 10 samples with respect to the mean value.

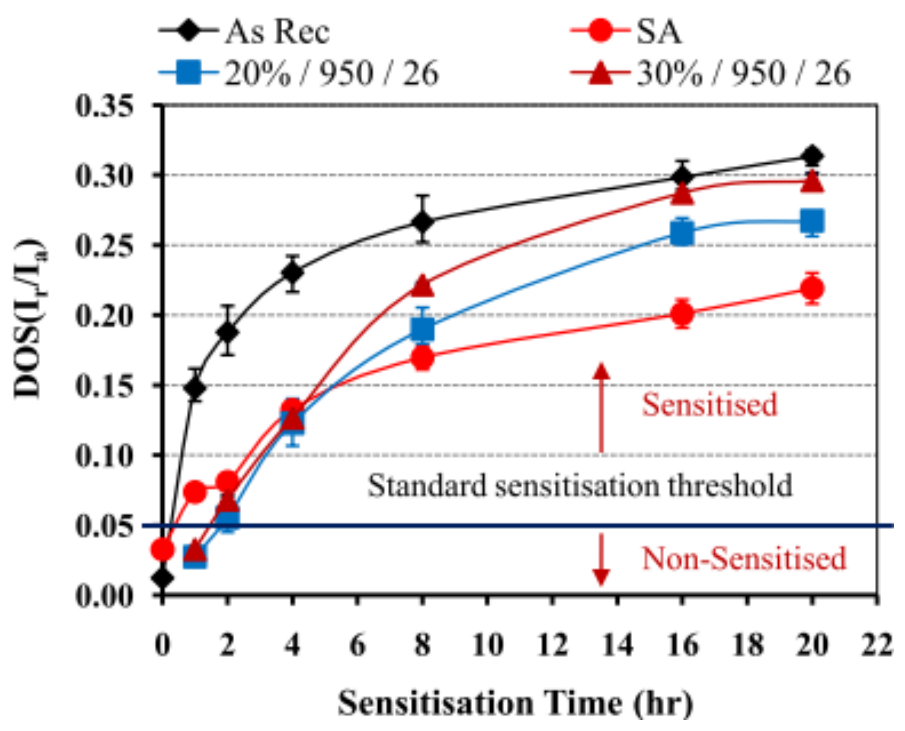

Figure 6: Degree of sensitisation (DOS) as functions of sensitisation time in the four selected microstructures. The error bars describe the maximum and minimum of three DL-EPR tests. The horizontal line at DOS 0.05 shows the standard sensitisation threshold for a fully sensitised microstructure $[16,17]$. 
The total surface area of the attacked grain boundary network $\left(M_{\text {Total }}\right)$ per unit area of sample, obtained by IA analysis after DL-EPR testing, is shown in Figure 7a as a function of sensitisation time for the four selected microstructures, and expressed as a percentage. As expected, longer sensitisation time increases the attacked area. The average width of attacked boundaries also increases with sensitisation time, before saturating at longer sensitisation exposures ( $>8$ hours) (Figure $7 \mathrm{~b}$ ). The length of the attacked boundaries (extracted by dividing the $M_{\text {Total }}$ by the average boundary width) increased with sensitisation time (Figure $7 \mathrm{c})$.

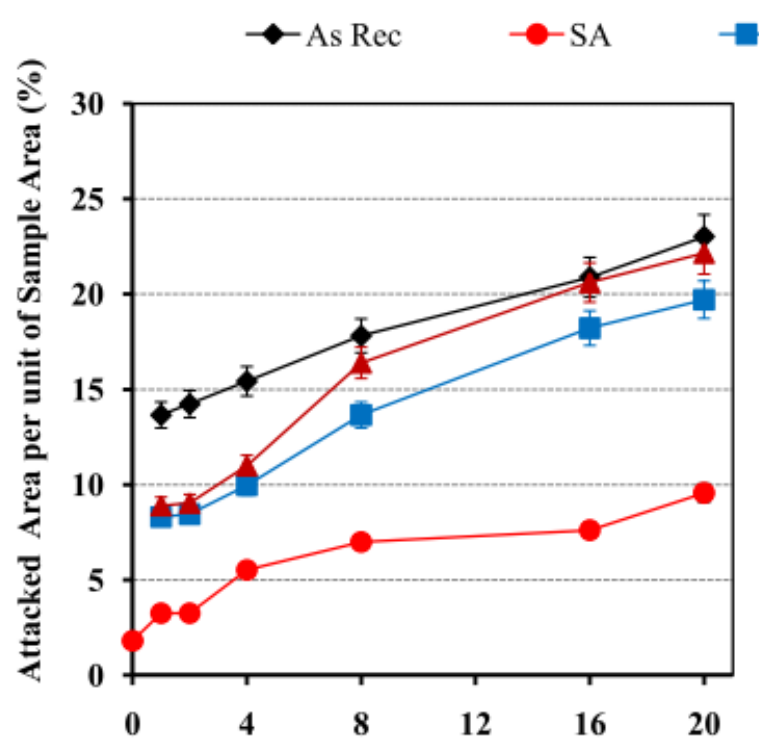

(a)
$-20 \% / 950 / 26-130 \% / 950 / 26$

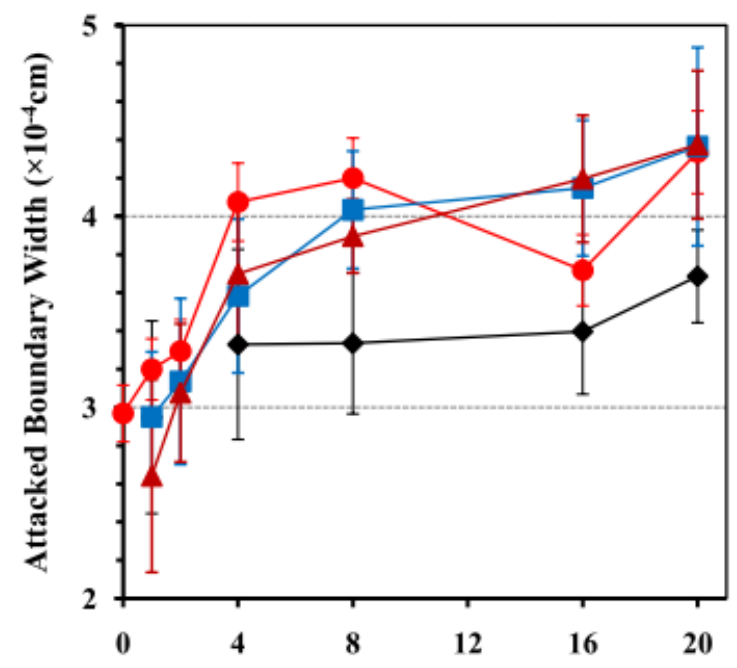

(b)

Sensitisation Time (hr)

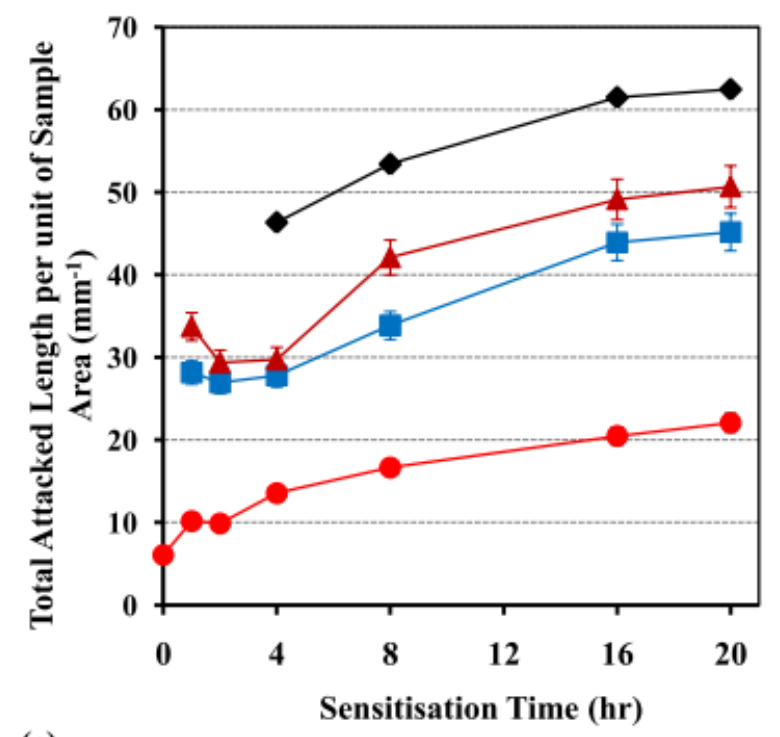

(c)

Figure 7: Effect of sensitisation on attacked grain boundary network dimensions in the four selected microstructures. (a) Attacked surface area per unit area with time, (b) attacked boundary width with time (error bars show the standard deviation), (d) attacked boundary length per unit area with time.

Figure 8 shows the development of DOS with sensitisation time, normalised using Cihal's method (Equation 2 and Equation 3, open symbols and dashed lines). The DOS was also calculated by normalising with the measured length and area of attacked grain boundaries 
from image analysis (closed symbols and solid lines). The measured attacked grain boundary length is generally smaller than that estimated by Equation 2, giving higher DOS values (Figure 8a). In contrast, the measured grain boundary area of attack is larger than that estimated by Equation 3, giving lower values of DOS (Figure 8b). The DOS obtained by normalising with the actual boundary dimensions show saturation as the sensitisation time increases.

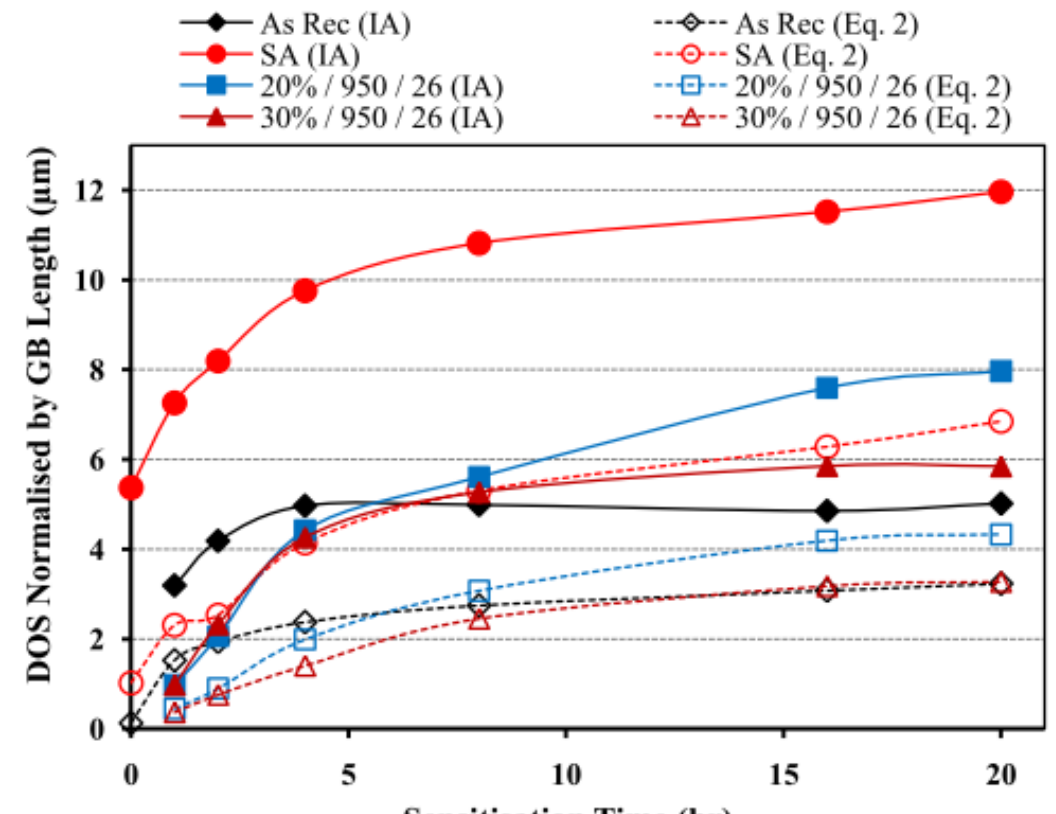

(a)

Sensitisation Time (hr)

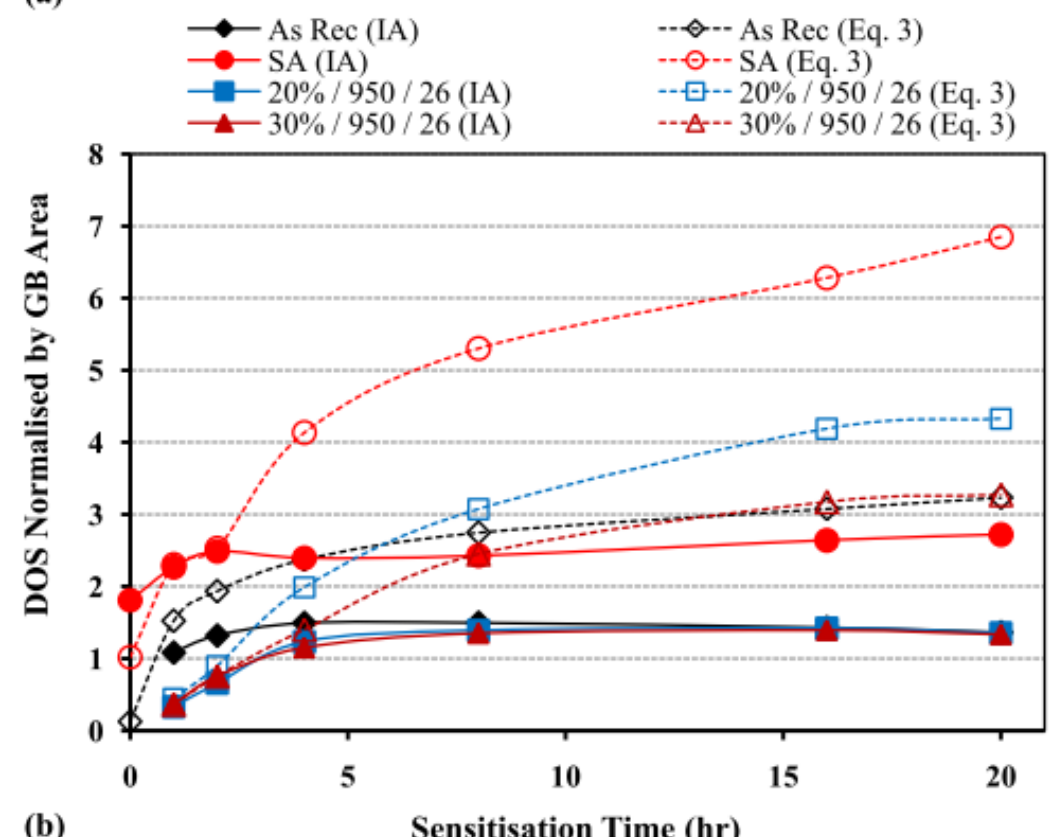

Figure 8: Normalised current ratios (DOS) as functions of sensitisation time at $650^{\circ} \mathrm{C}$ by (a) length of attacked boundaries measured using IA, and estimated grain boundary length (Eq. 2), and (b) area of attacked boundaries measured using IA, and estimated area of attacked boundaries (Eq. 3).

To further investigate the effect of normalisation by the measured dimensions of the attacked grain boundary network, all the microstructures in their fully sensitised condition ( 20 hours at $650^{\circ} \mathrm{C}$ ) were assessed. Data for their bulk microstructure characteristics are provided in 
Table 3, with the DOS obtained using Equation 1. The DOS values obtained by normalising with the estimated length and area of attacked grain boundaries (Equation 2 \& Equation 3 ) are compared in Figure 9 with the DOS obtained by normalising with the measured length and area. The four selected microstructures from Figure 8 are identified in Figure 9. The data for their shorter sensitisation times are also provided to aid comparison. This shows that the DOS obtained using the measured attacked grain boundary length is consistently higher than that estimated using Equation 2, and that the ratio of these values is not constant. Comparison of the DOS obtained using the two different area normalizations (Figure 9b) shows no clear trend.
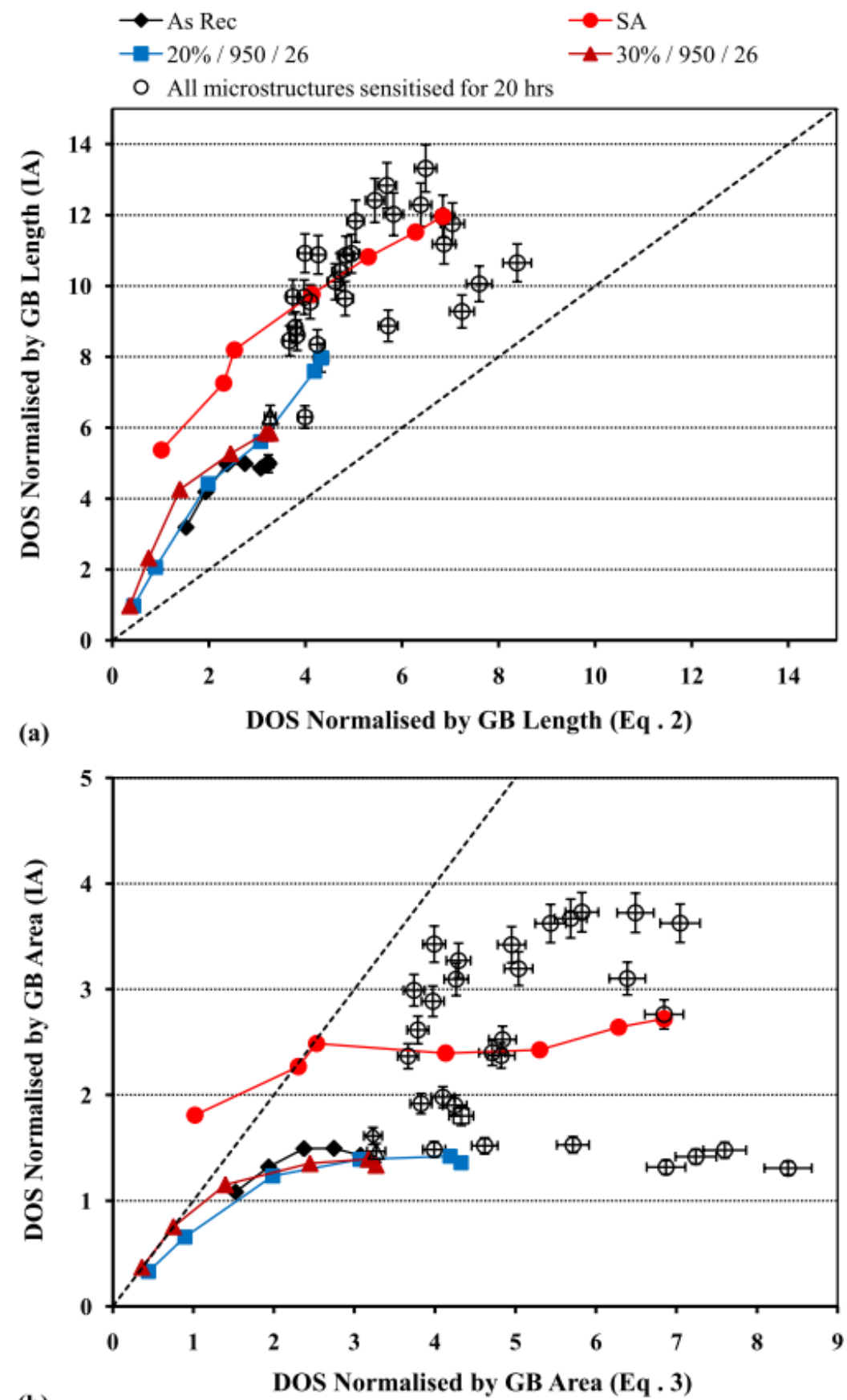

(b)

Figure 9: DOS normalised by estimated and measured grain boundary attack (IA) of all fully sensitised microstructures (see Table 2) for (a) the length of attacked grain boundary and (b) 
area of attacked grain boundaries. The data for the selected microstructures (Figure 8) sensitised for shorter times are also shown.

As the fraction of corrosion susceptible boundaries increases, the length of such boundaries in a cluster of a given size should decrease; hence the cluster compactness of the network of corrosion susceptible grain boundaries should increase (Equation 4). The estimate of grain boundary length (Equation 2) was therefore divided by the cluster compactness $\left(C_{O I A}\right)$ of the attacked grain boundary network, to investigate whether this gave a better estimate of the attacked grain boundary length. The DOS obtained using this measure for all microstructures (after 20 hours sensitisation) is shown in Figure 10a, compared with that obtained using the measured grain boundary length. The relative agreement is good, although the absolute values differ by a factor of 2 . This indicates that cluster compactness is a fair measure of the grain boundary network.

The cluster compactness of the network of non-special (i.e. corrosion susceptible) grain boundaries, $C_{E B S D}$, derived from analysis of the high $\Sigma(\Sigma>29)$ boundary network obtained from EBSD maps was also measured. The data for $C_{O I A}$ for the fully sensitised microstructures are compared with $C_{E B S D}$ in Figure $10 \mathrm{~b}$. The values obtained from EBSD characterisation are generally larger than those obtained from direct characterisation of the attacked network, but there is a broad agreement in trend of the data. The standard estimate (Equation 2) of grain boundary length was therefore divided by $C_{E B S D}$ to investigate whether this gave a fair estimate of the measured attacked grain boundary length. The data are shown in Figure 11(a), together with the effect on the DOS obtained. This shows that normalisation using cluster properties obtained from EBSD data is less accurate than direct measurement of the attacked grain boundaries, but the general agreement is fair.

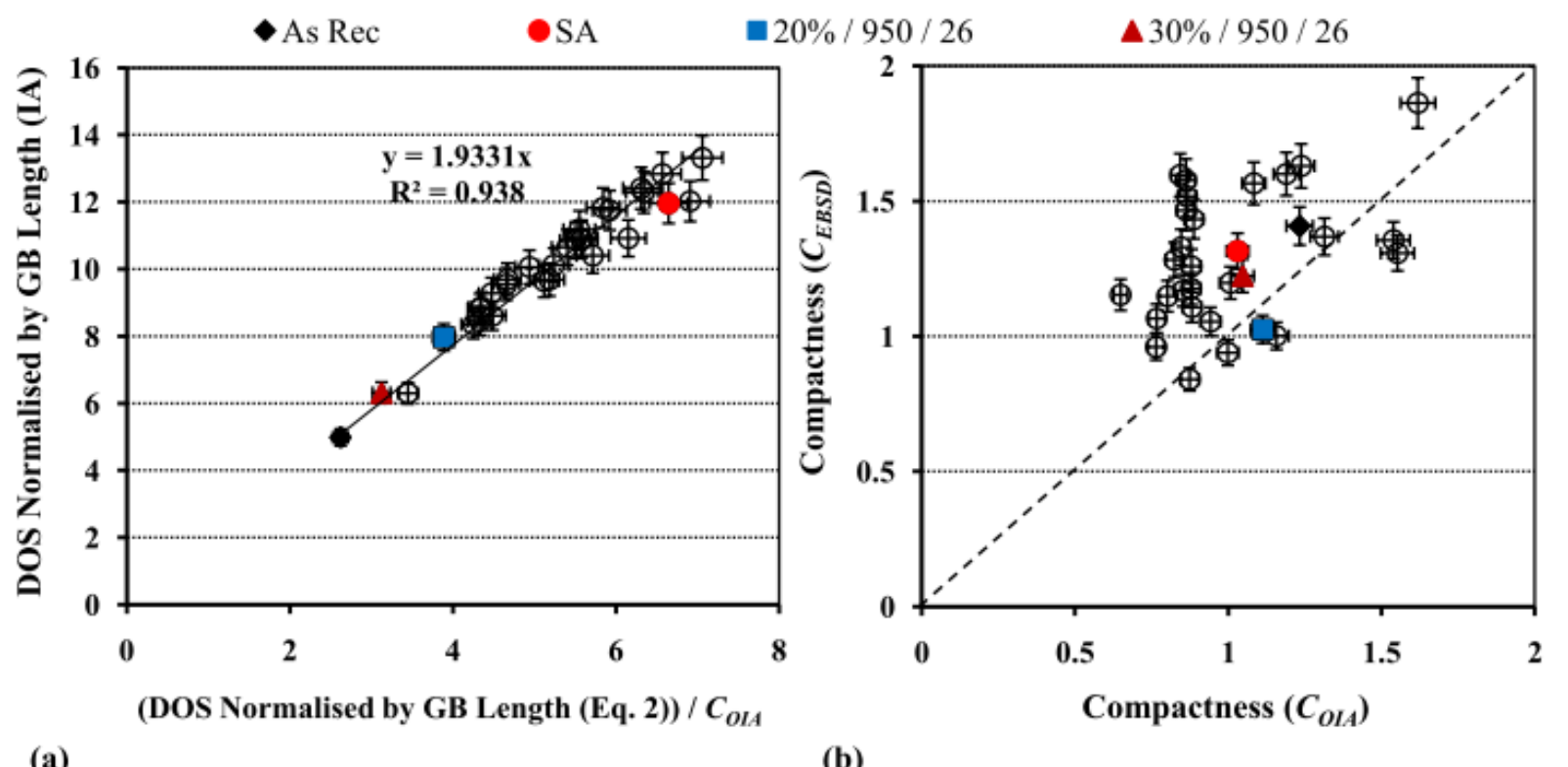

(a)

(b)

Figure 10: (a) Comparison between the DOS obtained by DL-EPR testing normalised by the attacked grain boundary length (measured using IA) to the DOS normalised by the estimated grain boundary length (Equation 2 ) and the cluster compactness $\left(C_{O I A}\right)$. (b) Comparison of the compactness of the attacked boundary network $\left(C_{O I A}\right)$ to the compactness of the network of potentially susceptible boundaries $(\Sigma>29)$ from EBSD analysis $\left(C_{E B S D}\right)$. 


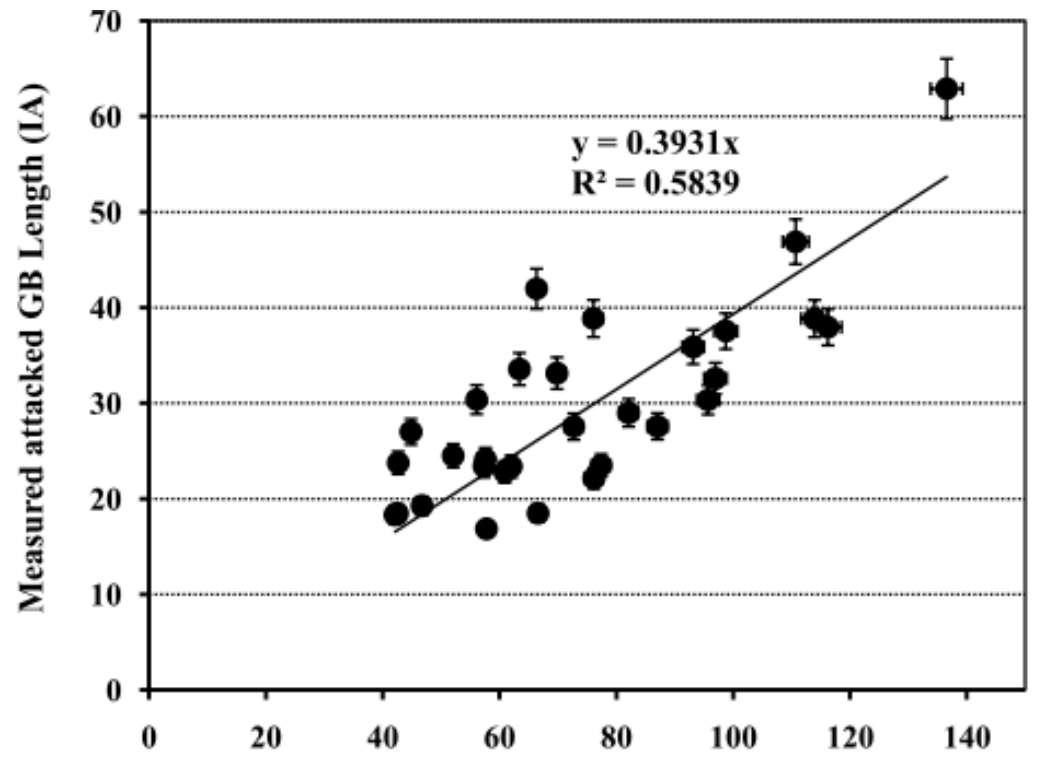

(a)

(Estimated GB Length (Eq . 2$)) \times \mathrm{C}_{\text {EBSD }}$

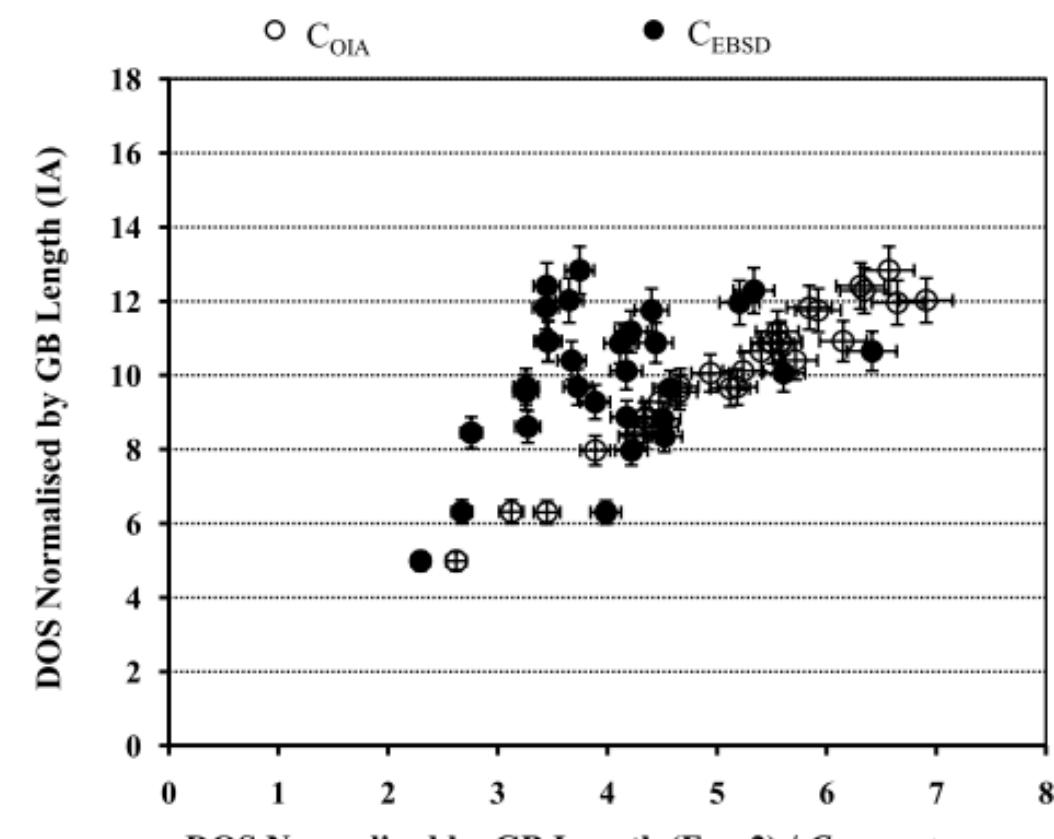

(b)

DOS Normalised by GB Length (Eq . 2) / Compactness

Figure 11: (a) Comparison between the DOS normalised by attacked grain boundary length measured by IA and the DOS normalised by expected grain boundary length using Cihal's (Equation 2) method and the cluster compactness obtained by both IA $\left(C_{O I A}\right)$ and EBSD $\left(C_{E B S D}\right.$ ), (b) DOS normalised by grain boundary length using Cihal's method (Equation 2) normalised by random boundary $(\Sigma>29)$ cluster compactness $\left(C_{E B S D}\right)$ as a function of that normalised by attacked boundary cluster compactness $\left(C_{O I A}\right)$ for all fully sensitised microstructures.

\section{Discussion}

In the DL-EPR test, the anodic polarisation in the acidic solution leads initially to active dissolution of the surface, producing the activation current peak $\left(I_{a}\right)$, which is followed by the formation of a passive film as the potential is increased. Hence the total charge, represented by the maximum activation current $\left(I_{a}\right)$, is primarily dependent on the sample size, as shown in Figure 5, and not the nature of microstructure or grain boundaries. After establishing the 
passive film (i.e. between $0 \mathrm{mV}$ to $+300 \mathrm{mV}$ SCE), the scan in the cathodic direction attacks the passive layer, with dissolution primarily taking place at corrosion susceptible regions that were depleted of chromium by the sensitisation treatment. Reaching the Flade potential, the grain boundaries with $\mathrm{Cr}$ contents lower than the stainless threshold (approx. 12\% $\mathrm{Cr}$ [9]) are selectively attacked, producing the re-activation current peak $\left(I_{r}\right)$. Its magnitude increases with the degree of chromium depletion. To a first approximation, this is related to the area of selective attack.

The simple measure of DOS (Equation 1) for each microstructure tends toward a saturated stable value with longer sensitisation time (Figure 6). This is a typical observation in austenitic stainless steels that contain little cold-work [32]. The gradual increase in DOS with longer sensitisation time is related to the kinetics of carbide formation and changes in the chromium concentration gradient at interfaces, which is controlled by the chromium diffusivity $[33,34]$.

Simple use of this measure of the DOS (Equation 1) is insufficient for ranking the degree of susceptibility of different microstructures to IG and IGSCC, although it may be used to judge whether a microstructure is sensitised, with values above 0.05 generally regarded to indicate sensitisation [12]. This is a quite conservative approach; all four investigated microstructures exceeded this threshold in less than 2 hours (Figure 6) with significant increases in their DOS thereafter. A microstructure with a smaller grain size has a higher density of grain boundaries compared to a microstructure with coarser grain size. Hence, this measure of DOS in the fully sensitised condition (i.e. 20 hours at $650^{\circ} \mathrm{C}$ ) is significantly higher for microstructures with finer grain sizes as a greater length and area of grain boundaries is attacked. Hence, the normalisation procedures (Equation 2 \& Equation 3) were developed to aid comparison of the degree of susceptibility in microstructures of different grain size.

Increases in the chromium-depleted area with sensitisation time occur in two ways that contribute to the DL-EPR currents. The first is the gradual augmentation of the width of the chromium-depleted zone with sensitisation time. This is due to growth of carbide particles at boundaries, accompanied by depletion of chromium in the surrounding regions. The second is the increase in the number of sensitised grain boundaries with the sensitisation of the less susceptible boundary types. This increases the length of the attacked grain boundaries. These effects are observed in Figure $7 \mathrm{~b}$ and Figure $7 \mathrm{c}$, respectively. Hence the attacked grain boundary area, which is the product of the attacked boundaries and the average attacked boundary width, is observed to increase (Figure 7a). This is consistent with previous observations of the area of attacked boundaries [20].

In the standard method of Cihal [16] a constant value for the attacked grain boundary width is assumed, with the attacked length estimated from the grain size. However, Figure 7a and Figure 7c show that the attacked grain boundary area and length increase with sensitisation time. The normalisation in the standard method is not sensitive to the sensitisation time, and grain boundary lengths calculated only using the grain size number [31] are therefore overestimates. For shorter sensitisation times, the DOS normalised by total grain boundary length using the standard method (Equation 2) is significantly smaller than the degree of sensitisation obtained using the measured attacked grain boundary length (Figure 8a). This implies that the standard normalisation by grain boundary length does not always provide a reliable measure for the DOS, particularly in microstructures with lower degrees of sensitisation. Normalisation by estimated grain boundary area using the standard method yields a higher degree of sensitisation compared to the actual DOS (Figure 8b). This is due to the inaccurate estimation of the attacked grain boundary width and area. 
The normalization in the standard method requires several assumptions. Firstly, it is assumed that the reactivation current $\left(I_{r}\right)$ is associated with grain boundary sensitisation only. Hence the contributions of corrosion at inclusions, $\delta$-ferrite/austenite interfaces, and attacked slip bands are neglected (In most cases, this does not cause significant error). Secondly, the degree of sensitisation of all grain boundaries is considered equal. Thirdly, the width of attack of all grain boundaries is assumed constant [16]. Figure 12 shows an EBSD map of a typical microstructure in a fully sensitised condition along with its corresponding back scatter (BS) image of the same area after DL-EPR testing. It can be clearly seen that all grain boundaries are not sensitised to the same degree. Those with low $\Sigma$ CSL values are generally resistant to sensitisation even after prolonged time, although the figure also shows that the CSL description is not sufficient to fully describe resistance since some low- $\Sigma$ boundaries are clearly attacked. These assumptions may lead to inaccuracy when comparing microstructures with different grain boundary character distributions, since sensitisation behaviour depends on the structure of grain boundaries [5, 24-26].

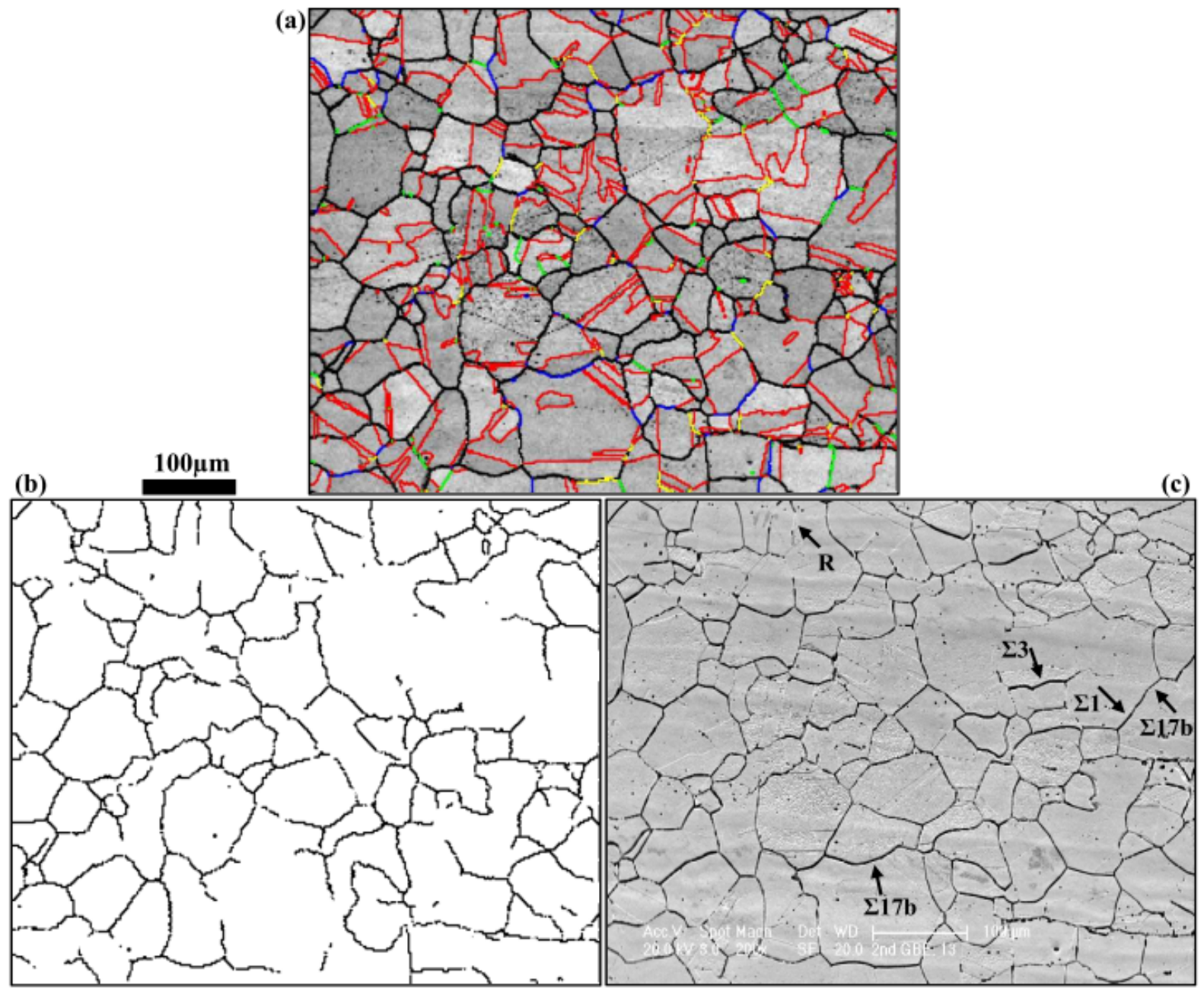

Figure 12: (a) EBSD grain boundary map of thermo-mechanically processed microstructure $(20 \%$ / $950 / 26)$, sensitised at $650^{\circ} \mathrm{C}$ for 20 hours. $\Sigma 3$ boundaries are represented in red, $\Sigma 9$ and 27 boundaries in yellow, low angle grain boundaries $(\Sigma 1)$ in green, the rest of low- $\Sigma$ CSL boundaries in blue and random boundaries in black, (b) the same map as in (a) with only the non-special $(\Sigma>29)$ boundaries highlighted, and (c) scanning electron microscopy (SEM) image of the same area after DL-EPR testing. 
The DOS, normalised by the actual attacked grain boundary length, gives a measure of the corrosion current per unit length of attacked grain boundary. This describes the average degree of sensitisation of the susceptible grain boundaries in the microstructure. The image analysis (IA) approach thus gives more accurate measure of the microstructure's degree of sensitisation. Errors will occur, however, if corrosion pits and attacked slip bands contribute significantly to the reactivation current $\left(I_{r}\right)$; this may occur in cold worked materials.

The attacked grain boundary cluster compactness $\left(C_{O I A}\right)$, when introduced to the standard method to assess DOS, (Figure 10a) shows that compactness and grain size can be used to estimate the total length of attacked boundaries with reasonable accuracy. The compactness $C_{O I A}$ is obtained from the same data as the attacked length, so it would be useful to have an alternative measure that did not require measurement of the attacked microstructure, such as $C_{E B S D}$. There is a general agreement between $C_{O I A}$ and $C_{E B S D}$ (Figure 10b), although EBSD assessment of cluster compactness does not fully agree with the optical assessment of the corroded boundaries in the fully sensitised condition. This is mainly due to the criteria used to define susceptible boundaries. For example, the EBSD assessment treats all $\Sigma 3$ boundaries similarly. However, the $\Sigma 3$ family consists of coherent and incoherent twin boundaries, and in most environments only coherent twin have shown resistance to corrosion $[5,26]$. Also, observations of the attacked boundary networks (Figure 12) show attacked boundaries with low $\Sigma$ CSL $(\Sigma \leq 29)$ value and vice versa, some boundaries with high $\Sigma$ are resistant to corrosion. Therefore, the networks of potentially susceptible boundaries acquired by EBSD do not necessarily represent the network of actual corrosion susceptible boundaries. The assessment of the EBSD network might be refined in future, by identifying the contribution of incoherent twins for example.

The broad agreement between $C_{O I A}$ and $C_{E B S D}$ [30] suggests that analysis of EBSD data can reasonably approximate the actual network of corrosion susceptible boundaries in the fully sensitised condition. Hence the maximum value of $C_{O I A}$ in a fully sensitised microstructure may be estimated by measurement of $C_{E B S D}$, without image analysis of the corrosion tested sample. A modification of the standard assessment, using image analysis to obtain a true measure of the attacked grain boundary length will provide a more accurate method for characterising sensitisation particularly in non-cold worked microstructures. This method may reveal more clearly the effects of composition on sensitisation, by reducing the effects of grain size and grain boundary character distribution. Assessment using $C_{E B S D}$, without the need for image analysis, may also improve comparison of the maximum degree of sensitisation in different heats and microstructures.

\section{Conclusion}

1. A new approach of normalising the degree of sensitisation by measurement of the attacked grain boundary network by image analyses (IA) has been introduced. This new approach is compared with the standard normalisation approach (Cihal's method).

2. This new approach measures the degree of sensitisation of the attacked grain boundaries more accurately than the standard method, particularly for short sensitisation times, and may be used to compare the sensitisation of microstructures that differ in grain size and grain boundary character distribution.

3. The length of the attacked grain boundary network can be described by a cluster compactness parameter, derived from image analysis.

4. The cluster compactness obtained by EBSD assessment of the microstructure can be used to estimate the maximum cluster compactness of the corrosion susceptible grain 
boundary network, and thereby to estimate the maximum degree of sensitisation of the microstructure.

\section{Acknowledgement}

This work was performed at Materials Performance Centre (MPC), School of Materials, The University of Manchester. DLE acknowledges financial support from Rolls-Royce PLC.

\section{References}

[1] P.M. Scott, Stress corrosion cracking in pressurized water reactors - interpretation, modelling, and remedies, Corrosion, 56 (2000) 771-782.

[2] S. M. Bruemmer, G. S. Was, Microstructural and microchemical mechanisms controlling intergranular stress corrosion cracking in light-water-reactor systems, Journal of Nuclear Materials, 216 (1994) 348-363.

[3] N. Parvathavarthini, S. Mulki, R. K. Dayal, I. Samajdar, K. V. Mani, B. Raj, Sensitisation control in AISI 316(N) austenitic stainless steel; Defining the role of the nature of grain boundary, Corrosion Science, 51 (2009) 2144-2150.

[4] E. A. Trillo, L. E. Murr, Effect of carbon content, deformation and interfacial energies on carbide precipitation and corrosion sensitisation in 304 stainless steel, Acta Materialia, 47 (1998) 235-245.

[5] Y. Zhou, K. T. Aust, U. Erb, G. Palumbo, Effects of grainboundary structure on carbide precipitation in 304L stainless steel, Scripta Materialia, 45 (2001) 49-54.

[6] V. Cihal, R. Stefec, On the development of the electrochemical potentiokinetic method, Electrochimica Acta, 46 (2001) 3867-3877.

[7] W. L. Clarke, V. M. Romero, J. C. Danko, Detection of sensitisation in stainless steels using electrochemical techniques, In: NACE/77, National Association of Corrosion Engineers, Houston, Texas, 1977.

[8] ASTM International, Standard Practice for determining the susceptibility to intergranular attack in Austenitic Stainless Steels, in: ASTM A262, 2001.

[9] N. Parvathavarthini, S. Mulki, R. K. Dayal, I. Samajdar, K. V. Mani, B. Raj, Sensitisation and testing for Intergranular Corrosion, in: H.S. Khatak, B. Raj (Ed.) Corrosion of Austenitic Stainless Steels. Mechanism, Mitigation and monitoring, Norasa Publishing House, New Delhi, 2002, pp. 117 - 138.

[10] R. K. Dayal, N. Parvathavarthini, B. Raj, Influence of Metallurgical Variables on Sensitisation Kinetics in Austenitic Stainless Steels, International Materials Reviews, 50 (2005) 129 - 155.

[11] M. Akashi, T. Kawamoto, F. Umemura, Evaluation of IGSCC susceptibility of austenitic stainless steels using electrochemical reactivation method, Corrosion Engineering, 29 (1980) $163-169$.

[12] A. P. Majidi, M. A. Streicher, The double loop reactivation test for detecting sensitisation in type 304 and 304L stainless steels, Corrosion, 40 (1984) 584 - 593.

[13] A. P. Majidi, M. A. Streicher, Four Nondestructive Electrochemical Tests for Detecting Sensitisation in Type 304 and 304L Stainless Steels, Nuclear Technology, 75 (1986) 356 369.

[14] M.C. N. Lopez, M. Puiggali, I. Azkarate, A. Pelayo, Applicaiton of Double Loop Electrochemical Potentiodynamic Reactivation Test to Austenitic and Dupelx SS, Materials Science and Engineering, A 229 (1997) 123-128.

[15] G. S. Was, V. B. Rajan, On the Relationship Between the EPR Test, Sensitisation, and IGSCC Susceptibility, Corrosion, 43 (1987) 576-579. 
[16] British Standards Institution, Corrosion of metals and alloys - Electrochemical potentiokinetic reactivation measurement using the double loop method (based on Cihal's method), in: BS ISO 12732, 2006.

[17] ASTM International, Electrochemical Reactivation (EPR) for Detecting Sensitisation of AISI Type 304 and 304L Stainless Steels, in: ASTM G108, 1999.

[18] M. Shimada, H. Kokawa, Z.J. Wang, Y.S. Sato, I. Karibe, Optimization of grain boundary character distribution for intergranular corrosion resistant 304 stainless steel by twin induced grain boundary engineering, Acta Materialia, 50 (2002) 2331- 2341.

[19] S. R. Ortner, V. Randle, A study of the relation between grain boundary type and sensitisation in a partially sensitised AISI 304 stainless steel using electron back-scattering patterns, Scripta Metallurgica, 23 (1989) 1903-1908.

[20] S. Rahimi, D. L. Engelberg, T. J. Marrow, Characterisation of Grain Boundary Cluster Compactness in an Austenitic Stainless Steel, Journal of Materials Science and Technology, 26 (2010) 670-675.

[21] S. Rahimi, Behaviour of Short Intergranular Stress Corrosion Crack in Type 304 Austenitic Stainless Steel: PhD Thesis, in: School of Materials, The University of Manchester, Manchester, 2010.

[22] H. Grimmer, W. Bollmann, D. H. Warrington, Coincidence site lattices and complete pattern-shift lattices in cubic crystals, Acta Crystallographica A, 30 (1974) 197-207.

[23] D. G. Brandon, The structure of high angle grain boundaries, Acta Metallurgica, 14 (1966) 1479-1484.

[24] V. Y. Gertsman, S. M. Bruemmer, Study of grain boundary character along intergranular stress corrosion crack paths in austenitic alloys, Acta Materialia, 49 (2001) 1589-1598.

[25] S. Rahimi, D. L. Engelberg, J. A. Duff, T. J. Marrow, In situ observation of intergranular crack nucleation in a grain boundary controlled austenitic stainless steel, Journal of Microscopy, 233 (2009) 423-431.

[26] H. Kokawa, M. Shimada, Y. S. Sato, Grain-boundary structure and precipitation in sensitized austenitic stainless steels, Journal of the Minerals Metals and Materials Society, 52 (2000) 34-37.

[27] A. King, G. Johnson, D. L. Engelberg, T. J. Marrow, W. Ludwig, Observations of Intergranular Stress Corrosion Cracking in a Grain-Mapped Polycrystal, Science, 321 (2008) $382-385$.

[28] L. Babout, T.J. Marrow, D. L. Engelberg, P. J. Withers, X-ray microtomographic observation of intergranular stress corrosion cracking in sensitised austenitic stainless steel, Materials Science and Technology, 22 (2006) 1068-1075.

[29] T. J. Marrow, L. Babout, B. J. Connolly, D. L. Engelberg, G. Johnson, J. Y. Buffiere, R. C. Newman, High Resolution in-situ, Tomographic Observations of stress corrosion cracking, in: EICM-2, Canada, 2004.

[30] S. Rahimi, D.L. Engelberg, T.J. Marrow, Characterisation of the sensitisation behaviour of thermo-mechanically processed type 304 stainless steel using DL-EPR testing and image analysis methods, in: 2nd International Conference, Corrosion and Material Protection, Prague, Czech Republic, 2010.

[31] British Standards Institution, Steels - Micrographic determination of the apparent grain size, in: BS EN ISO 643, 2003.

[32] A. H. Advani, R. J. Romero, L. E. Murr, D. J. Matlock, W. W. Fisher, P. M. Tarin, C. M. Cedillo, J. G. Maldonado, R. L. Miller, E. A. Trillo, Deformation effects on interfacial carbide precipitation and chromium-depletion in type 304 stainless steel, Scripta Metallurgica, 27 (1992) 1759-1764.

[33] T. Thorvaldsson, G. L. Dunlop, Grain boundary Cr-depleted zones in $\mathrm{Ti}$ and $\mathrm{Nb}$ stabilized austenitic stainless steels, Journal of Materials Science, 18 (1983) 793-803. 
[34] C. Strawstrom, M. Hillert, An improved depleted-zone theory of intergranular corrosion of 18-8 stainless steel, Journal of the Iron and Steel Institute, 207 (1969) 77-85. 